\title{
Multimodal Imaging of Nanovaccine Carriers Targeted to Human Dendritic Cells
}

\author{
Luis J. Cruz, ${ }^{\dagger}$ Paul J. Tacken, ${ }^{\dagger}$ Fernando Bonetto, ${ }^{\dagger}$ Sonja I. Buschow, ${ }^{\dagger}$ Huib J. Croes, ${ }^{\ddagger}$ Mietske Wijers, ${ }^{\ddagger}$ \\ I. Jolanda de Vries, ${ }^{+}$and Carl G. Figdor ${ }^{*,+}$
}

${ }^{\dagger}$ Department of Tumor Immunology, Nijmegen Centre for Molecular Life Sciences, University Medical Centre, Nijmegen, The Netherlands

${ }^{\ddagger}$ Department of Cell Biology, Nijmegen Centre for Molecular Life Sciences, Radboud University Nijmegen Medical Centre, Nijmegen, The Netherlands

Supporting Information

\begin{abstract}
Dendritic cells (DCs) are key players in the initiation of adaptive immune responses and are currently exploited in immunotherapy against cancer and infectious diseases. The targeted delivery of nanovaccine particles (NPs) to DCs in vivo is a promising strategy to enhance immune responses. Here, targeted nanovaccine carriers were generated that allow multimodal imaging of nanocarrier-DC interactions from the subcellular to the organism level. These carriers were made of biodegradable poly(D,L-lactide-co-glycolide) harboring superparamagnetic iron oxide particles (SPIO) and fluores-

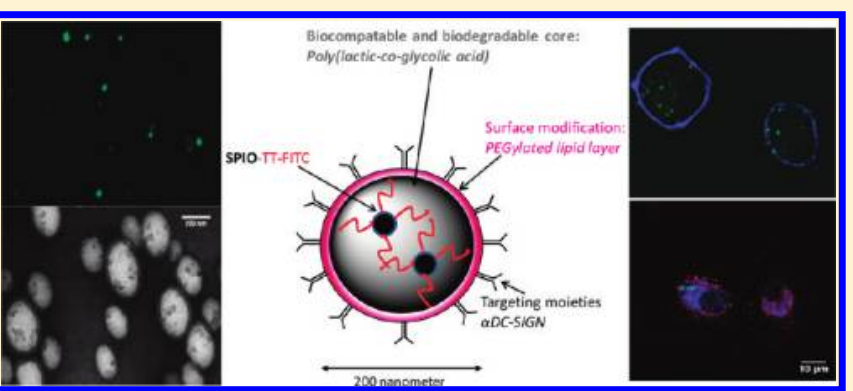
cently labeled antigen in a single particle. Targeted delivery was facilitated by coating the NPs with antibodies recognizing the DC-specific receptor DC-SIGN. The fluorescent label allowed for rapid analysis and quantification of specific versus nonspecific uptake of targeted NPs by DCs compared to other blood cells. In addition, it showed that part of the encapsulated antigen reached the lysosomal compartment of DCs within 24 h. Moreover, the presence of fluorescent label did not prevent the antigen from being presented to antigen-specific T cells. The incorporated SPIO was applied to track the NPs at subcellular cell organel level using transmission electron microscopy (TEM). NPs were found within endolysosomal compartments, where part of the SPIO was already released within $24 \mathrm{~h}$. Furthermore, part of the NPs seemed to localize within the cytoplasm. Ex vivo loading of DCs with NPs resulted in efficient labeling and detection by MRI and did not abolish cell migration within collagen scaffolds. In conclusion, incorporation of two imaging agents within a single carrier allows tracking of targeted nanovaccines on a subcellular, cellular and possibly organism level, thereby facilitating rational design of in vivo targeted vaccination strategies.
\end{abstract}

KEYWORDS: imaging, nanocarriers, biocompatible materials, contrast agents, fluorescence, magnetic resonance imaging, nanoparticles, dentritic cells

\section{INTRODUCTION}

Immunotherapeutic strategies involving the induction of antigen-specific immune responses depend on accurate delivery of antigen to professional antigen presenting cells (APCs), such as dendritic cells (DCs). DCs play a key role in regulating antigen-specific immunity. DCs reside in peripheral tissues in an immature differentiation state in which they actively sample their environment for the presence of pathogens. Upon ingestion of pathogens, DCs mature and migrate throughout the vascular and lymphatic system to present acquired antigens to $\mathrm{T}$ cells located within lymph nodes. During this process efficient uptake of antigen by DCs and induction of DC migration to regional lymph nodes are essential to trigger effective immune responses. ${ }^{1}$

Currently, DCs loaded ex vivo with tumor antigens are investigated for their ability to induce antigen-specific $\mathrm{T}$ cell responses in clinical trials. However, objective clinical responses are thus far limited to a minority of patients. This might partly be explained by the low percentage of injected DCs that actually migrate to the lymph nodes to activate the immune system. ${ }^{2}$ To overcome this problem and to reduce the high costs involved with ex vivo culturing of autologous DCs, vaccination strategies are developed to specifically target antigens and maturation stimuli to DCs in vivo. ${ }^{3}$ Further development and validation of such vaccination strategies requires noninvasive imaging methods to track antigen and DCs in vitro and in vivo. ${ }^{4}$

Several noninvasive imaging techniques for the in vivo tracking of targeted nanostructures and injected DCs have been reported. They include the use of gamma-radiation-emitting radionuclides, such as indium-111 oxinate (planar gamma

Received: October 19, 2010

Accepted: $\quad$ March 7, 2011

Revised: February 8, 2011

Published: March 07, 2011 
scintigraphy), ${ }^{4,5}$ fluorine-18 (PET), ${ }^{6}$ luciferase (bioluminescence imaging), ${ }^{7}$ and iron oxide magnetic nanoparticles (MRI). ${ }^{5,8,9}$ The signal emanating from the nanoparticle or cell needs to be combined with anatomical information. Presently, magnetic resonance imaging (MRI) is among the best noninvasive techniques used in clinical medicine for assessing anatomy and function of tissues. In addition, MRI offers several advantages such as excellent temporal and spatial resolution, no direct exposure to radioactive compounds, rapid in vivo acquisition of images and a long effective imaging window. Dextran- or carboxydextran-coated superparamagnetic iron oxide particles (SPIO) nanoparticles, such as Feridex or Resovist, are the most commonly used and clinically approved SPIO-based MRI contrast agents. ${ }^{10,11}$ For in vivo tracking of particles, different approaches using various coating or encapsulation strategies for iron magnetic nanoparticles in liposomes or poly(lactide-co-glycolide) (PLGA) have been reported. ${ }^{12-14}$ However, most approaches lack specific targeting signals and thus result in inefficient accumulation of particles in target cells, thereby hampering detection of cells by MRI. Although useful at the anatomical level, MRI is much less sensitive than fluorescence imaging when used to monitor small tissue lesions, molecular activity, or cellular activities. By the integration of both MR and optical imaging techniques, the limitations of each technique can be offset by the other. Therefore, a combination of fluorescence and SPIO labeling could together provide essential information to track nanovaccine particles (NPs) and immunotherapeutic DCs. ${ }^{15-19}$

The development of nanovaccine-based multimodal imaging contrast agents that specifically target DCs provide additional advantages over conventional SPIO-loaded DC vaccines: ${ }^{20,21}(\mathrm{i})$ Due to the synergistic magnetism of the multiple iron oxide particles present within a single PLGA NP the relaxivity (R2), a measure of MR contrast, of SPIO encapsulated within PLGA NPs is larger than that of free SPIO; ${ }^{12}$ (ii) controlled release of antigen from PLGA enhances immune responses induced by the vaccine; (iii) targeted delivery to DCs should increase the cell specific uptake of contrast agents, thereby improving signal intensity in MRI; (iv) the circulation time in blood might be enhanced by the use of PEG-coated PLGA NPs; $;^{23,24}$ (v) and the multifunctional PLGA NPs should allow monitoring of DC migration via lymphatic drainage into lymph nodes in real time by noninvasive MRI techniques, while internalization and antigen processing can be studied at the cellular level using fluorescence.

In this study we encapsulated a fluorescent FITC-labeled peptide antigen and iron oxide within NPs composed of the biocompatible polymer PLGA. Moreover, an antibody recognizing the human DC-specific antigen receptor DC-SIGN was grafted onto the particle surface to ensure specific delivery of NPs to DC. We show that incorporation of FITC-peptide in NPs was suitable for confocal/fluorescence microscopy and FACS analysis, while the inclusion of iron oxide nanoparticles allowed tracking by transmission electron microscopy (TEM) and MRI. Moreover, the encapsulated peptide antigen was presented to $\mathrm{T}$ cells, indicating imaging results can be directly linked to immunological outcome.

\section{MATERIALS AND METHODS}

2.1. Materials and Reagents. PLGA (Resomer RG $502 \mathrm{H}$, lactide:glycolide molar ratio 48:52 to 52:48) was purchased from Boehringer Ingelheim, Germany. Solvents for peptide synthesis and PLGA preparation (dichloromethane (DCM), 2-propanol,
$\mathrm{N}, \mathrm{N}$-dimethylformamide (DMF) and ethyl acetate) were obtained from Sigma-Adrich (The Netherlands). Lipids purchased from Avanti Polar Lipids (USA) include 1,2-distearoyl-sn-glycero3-phosphoethanolamine- $\mathrm{N}$-[carboxyl(polyethylene glycol)2000] (ammonium salt) and 1,2-distearoyl-sn-glycero-3-phosphoethanolamine- $N$-[methoxy(polyethylene glycol)-2000] (ammonium salt) (mPEG $2000 \mathrm{PE}$ ). Iron(III) chloride hexahydrate $\left(\mathrm{FeCl}_{3} \cdot 6 \mathrm{H}_{2} \mathrm{O}\right)$ pure granulated, $99 \%$, iron(II) chloride tetrahydrate $\left(\mathrm{FeCl}_{2} \cdot 4 \mathrm{H}_{2} \mathrm{O}\right) 99 \%$, ammonium hydroxide $(5 \mathrm{M})$, oleic acid, PEG diamine were purchased from Fisher Scientific (USA). EDAC (1-ethyl-3-[3-dimethylaminopropyl] carbodiimide) and NHS ( $N$-hydroxisuccinimide) were obtained from Pierce (USA).

The following antibodies were used: anti-human HLA-DR/ DP clone Q5/13, ${ }^{25}$ Alexa Fluor 647-labeled goat anti-human and goat anti-mouse IgG (Invitrogen, The Netherlands). Humanized anti-DC-SIGN (hD1) and its isotype control (h5G1.1) were described before ${ }^{26,27}$ and were kindly provided by Alexion Pharmaceuticals (USA).

2.2. Peptide Synthesis. The TT epitope comprises the 830-844 region of tetanus toxoid. Fluorescein isothiocyanate (FITC) and TT epitopes were linked by a Lys-Lys cathepsin-like cleavage site. The peptide antigen (FITC-KKQYIKANSKFIGITELKK) with the extreme $\mathrm{N}$-terminal modified with FITC was synthesized manually according to standard protocols of solidphase peptide synthesis, using the Fmoc/tert-butyl strategy and CTC resin. ${ }^{28}$ N $\alpha$-Fmoc-protected amino acids were incorporated using 1-hydroxybenzotriazole (HOBt) and $N, N^{\prime}$-diisopropylcarbodiimide (DIPCDI) in DMF for $1.5 \mathrm{~h}$ and monitored by Kaiser ninhydrin tests. ${ }^{29}$ The Fmoc-protecting group was cleaved with a $20 \%$ piperidine solution in DMF $(2 \times 10 \mathrm{~min})$. After completion of the sequence, the peptide-resin was labeled with FITC (5 equiv) and DIEA (10 equiv) in a 9:1 mixture of DMF: DCM and then added to the peptide-resin and stirred for $12 \mathrm{~h}$. The FITC-TT peptide was cleaved from the CTC resin with TFA-DCM (1:99). The cleavage solution was removed by evaporation under reduced pressure. The lateral chains were completely removed by treatment with TFA: $\mathrm{H}_{2} \mathrm{O}$ :TES $(95: 2.5: 2.5 \mathrm{v} / \mathrm{v} / \mathrm{v})$ for $2 \mathrm{~h}$. The crude peptide product showed purity greater than $85 \%$ by RP-HPLC.

2.3. Preparation of SPIO and Conjugation of Peptide to SPIO. SPIO were fabricated as described by Kumar et al. In brief, ${ }^{30}$ SPIO were synthesized under inert atmospheric conditions through reduction of $\mathrm{FeCl}_{3}$ and $\mathrm{FeCl}_{2}$ salts using $\mathrm{NH}_{4} \mathrm{OH}$ solution at room temperature to obtain a black precipitable of SPIO. Next, the SPIO was recovered with methacrylic acid for $2 \mathrm{~h}$ at $70{ }^{\circ} \mathrm{C}$ in presence of $\mathrm{K}_{2} \mathrm{~S}_{2} \mathrm{O}_{8}$. SPIO- $\mathrm{COOH}$ were purified by centrifugation and washed several times with water. Subsequently, FITC-TT-peptide was covalently attached via amide bond to the SPIO using carbodiimide at room temperature. Briefly, SPIO $(100 \mathrm{mg} / \mathrm{mL})$ containing carboxyl groups on the surface were activated with EDAC (10 equiv) and NHS (10 equiv) for $1 \mathrm{~h}$ in the presence of isotonic 0.1 M MES saline buffer $\mathrm{pH}$ 5.5. MES buffer was used for slowing down hydrolysis of the NHS esters on the SPIO because it lacks amino and carboxyl groups, which could compete in the reaction. The SPIO were then recovered using a magnet, thereby removing excess EDAC/NHS and the watersoluble isourea byproduct. Activated SPIO were resuspended in $1 \mathrm{~mL}$ of PBS buffer and reacted with the amino group at the C-terminal of the FITC-TT-KK for $3 \mathrm{~h}$ at room temperature. Unbound peptide was removed by magnetic separation, and the FITC-TT-SPIO was washed three times with PBS. The unbound FITC-TT peptide was measured by fluorescence (492 nm 
Table 1. Nanovaccine Characterization ${ }^{a}$

$\begin{array}{lcccccc}\text { samples } & \begin{array}{c}\text { antigen FITC-TT } \\ (\mu \mathrm{g} / \mathrm{mg} \text { PLGA })\end{array} & \begin{array}{c}\text { SPIO } \\ (\mu \mathrm{g} / \mathrm{mg} \text { PLGA })\end{array} & \begin{array}{c}\text { size } \pm \text { SD } \\ (\mathrm{nm})\end{array} & \text { PDI } \pm \text { SD } & \begin{array}{c}\text { zeta potential } \pm \text { SD } \\ (\mathrm{mV})\end{array} & \begin{array}{c}\text { antibodies } \\ (\mu \mathrm{g} / \mathrm{mg} \text { PLGA })\end{array} \\ \text { NP } & 16.3 \pm 4.1 & 320 \pm 60 & 199.4 \pm 6.8 & 0.111 \pm 0.045 & -34.9 \pm 3.6 & \\ \text { NP-Isot } & 16.3 \pm 4.1 & 320 \pm 60 & 225.6 \pm 12.6 & 0.117 \pm 0.056 & -14.5 \pm 4.6 & 19.3 \pm 1.8 \\ \text { NP-hD1 } & 16.3 \pm 4.1 & 320 \pm 60 & 227.8 \pm 11.2 & 0.197 \pm 0.066 & -12.7 \pm 3.5 & 18.1 \pm 1.5\end{array}$

${ }^{a}$ Determination of FITC-TT peptide, size distribution and zeta potential of PLGA nanoparticles loaded with SPIO. NP-hD1 and NP-isotype and without Abs were characterized by DLS and zeta potential measurements. Particle size data represent the mean value \pm SD of dynamic light scattering data. Zeta potential data represent the mean value $\pm S D$ of 5 readings. Change in zeta potential, as well as the increase in sizes and distribution of the particles, clearly indicates that Abs were efficiently conjugated to the PLGA nanoparticles surface. FITC-TT antigen content of PLGA nanoparticles was determined by particle digestion and measuring fluorescence relative to standard curves. Data represent $\%$ of encapsulated antigen relative to the amount of antigen added during particle formation $\pm S D$ of experiments performed in triplicate. The amount of antibody introduced onto nanovaccine was determined by Coomassie dye protein assay and is depicted as the mean \pm SD of two experiments.

excitation and $520 \mathrm{~nm}$ emission) relative to a standard curve using a CytoFluor II (Applied Biosystem, Foster City, CA). The amount of FITC-TT peptide that bound to $1 \mathrm{mg}$ of SPIO was around $50.8 \pm$ $5.3 \mu \mathrm{g}$. The conjugation efficiency was approximately $50 \%$.

2.4. NP Preparation. PLGA NPs with entrapped FITC-TT peptide conjugated SPIO were prepared using an o/w emulsion and solvent evaporation-extration method. ${ }^{31}$ In brief, $90 \mathrm{mg}$ of PLGA in $3 \mathrm{~mL}$ of DCM containing the FITC-TT-SPIO (50 mg/mL) were added dropwise to $25 \mathrm{~mL}$ of aqueous $2 \%$ (w/ v) PVA in distilled water and emulsified for $90 \mathrm{~s}$ using a sonicator (Branson, sonofier 250). A combination of lipids (DSPE-PEG(2000)carboxylic acid (6 mg) and mPEG 2000 PE (6 mg)) were dissolved in DCM and added to the vial. The DCM was removed by a stream of nitrogen gas. Subsequently, the emulsion was rapidly added to the vial containing the lipids and the solution was homogenized during $30 \mathrm{~s}$ using a sonicator. Following overnight evaporation of the solvent at $4{ }^{\circ} \mathrm{C}$, the NPs were collected by ultracentrifugation at $60000 \mathrm{~g}$ for $30 \mathrm{~min}$, washed three times with distilled water and lyophilized.

2.5. Determination of FITC-Peptide-SPIO Content of the NPs. FITC-peptide-SPIO entrapment efficiency was determined by digesting $10 \mathrm{mg}$ of NPs in $1 \mathrm{~mL}$ of $0.8 \mathrm{~mol} / \mathrm{L} \mathrm{NaOH}$ overnight at $37^{\circ} \mathrm{C}$. The FITC-peptide-SPIO was separated by magnetic field and washed three times with distilled water. The amount of FITC-peptide-SPIO was determined by weighing after lyophilized samples of the preparation and the FITCpeptide-SPIO was also measured by fluorescence relative to standard curve (492 nm excitation and $520 \mathrm{~nm}$ emission) using a CytoFluor II (Applied Biosystem, Foster City, CA). The amount of FITC-peptide-SPIO encapsulated in $10 \mathrm{mg}$ of PLGA was around $3.2 \pm 0.6 \mathrm{mg}$ of FITC-peptide-SPIO.

2.6. Conjugating Antibodies to the NPs. Antibodies were conjugated to the DSPE-PEG(2000)carboxyl-containing PLGA NP-FITC-TT-SPIO preparation. Subsequently, particles were activated with EDAC and $N$-hydroxisuccinimide in MES buffer ( $\mathrm{pH}$ 6.0) during $1 \mathrm{~h}$ at room temperature. The activated carboxyl-NP was washed three times with MES buffer by centrifugation. Subsequently, antibodies (200 $\mu \mathrm{g}$ per $\mathrm{mg}$ of $\mathrm{NP}$ ) were added and the solution was stirred during $3 \mathrm{~h}$ at room temperature. Unbound antibodies were removed by centrifugation (10000g, during $10 \mathrm{~min}$ ) and the NP-hD1 and NP-isotype were washed three times with PBS. The presence of $\mathrm{hD} 1$ and h5G1.1 on the particle surface was confirmed by staining NPs with goat anti-human secondary antibodies, followed by analysis on a FacsCalibur flow cytometer using CellQuest software (BD Biosciences, USA) (see Supporting Information, Figure S1).

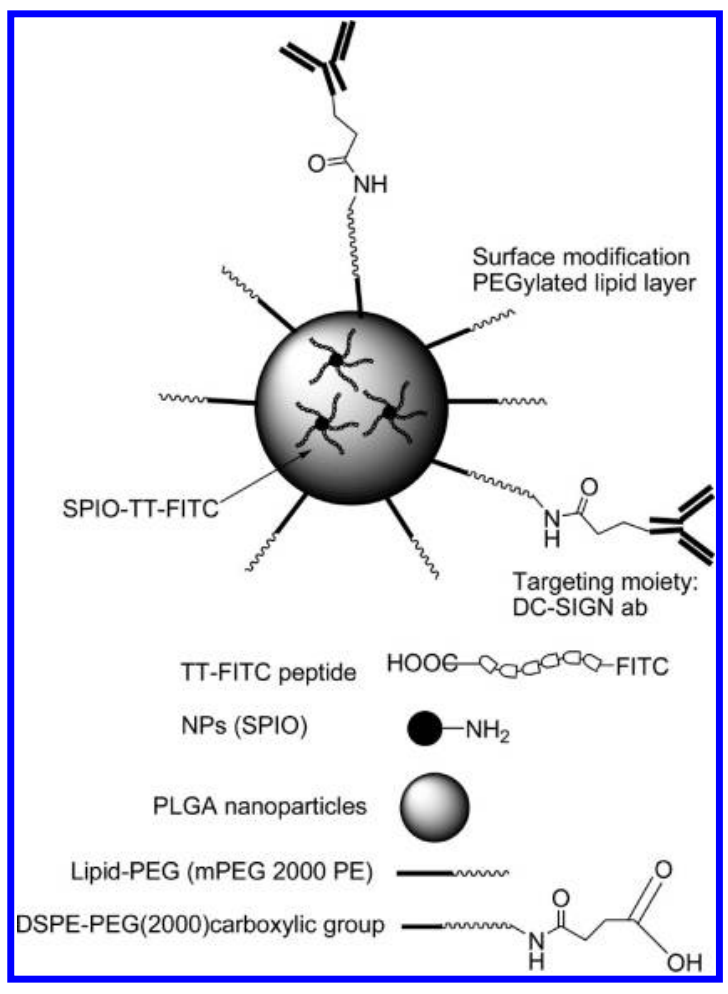

Figure 1. Schematic illustration of targeted nanovaccine carrier. NPs were generated containing iron oxide nanoparticles as MRI contrast agent and FITC as fluorescent label for flow cytometry and confocal optical imaging purposes. SPIO nanoparticles and FITC-TT peptide, which was covalently bound to the SPIO nanoparticles, were encapsulated into the PLGA matrix by a single emulsion method. The nanoparticles were shielded by a combination of PEG-lipid and carboxyl functionalized PEG-lipid layers. The PEG-lipid prevents nonspecific interactions, and the carboxyl functionalized PEG-lipid allows introduction of antibodies on the PLGA surface.

Quantification of antibodies (Abs) on the particle surface was perfomed by Coomassie dye protein assay (Table 1$).^{32}$

2.7. Scanning Electron Microscopy (SEM). NP morphology was studied by SEM. NPs were transferred to metallic stubs with double-sided conductive tape. Subsequently, samples were ioncoated with gold with a sputter coater (EDWARDS, Scan coat, United Kingdom) for $180 \mathrm{~s}$ in a vacuum at a current intensity of $40 \mathrm{~mA}$. Samples were analyzed on a Jeol JSM-6310 scanning electron microscope. 


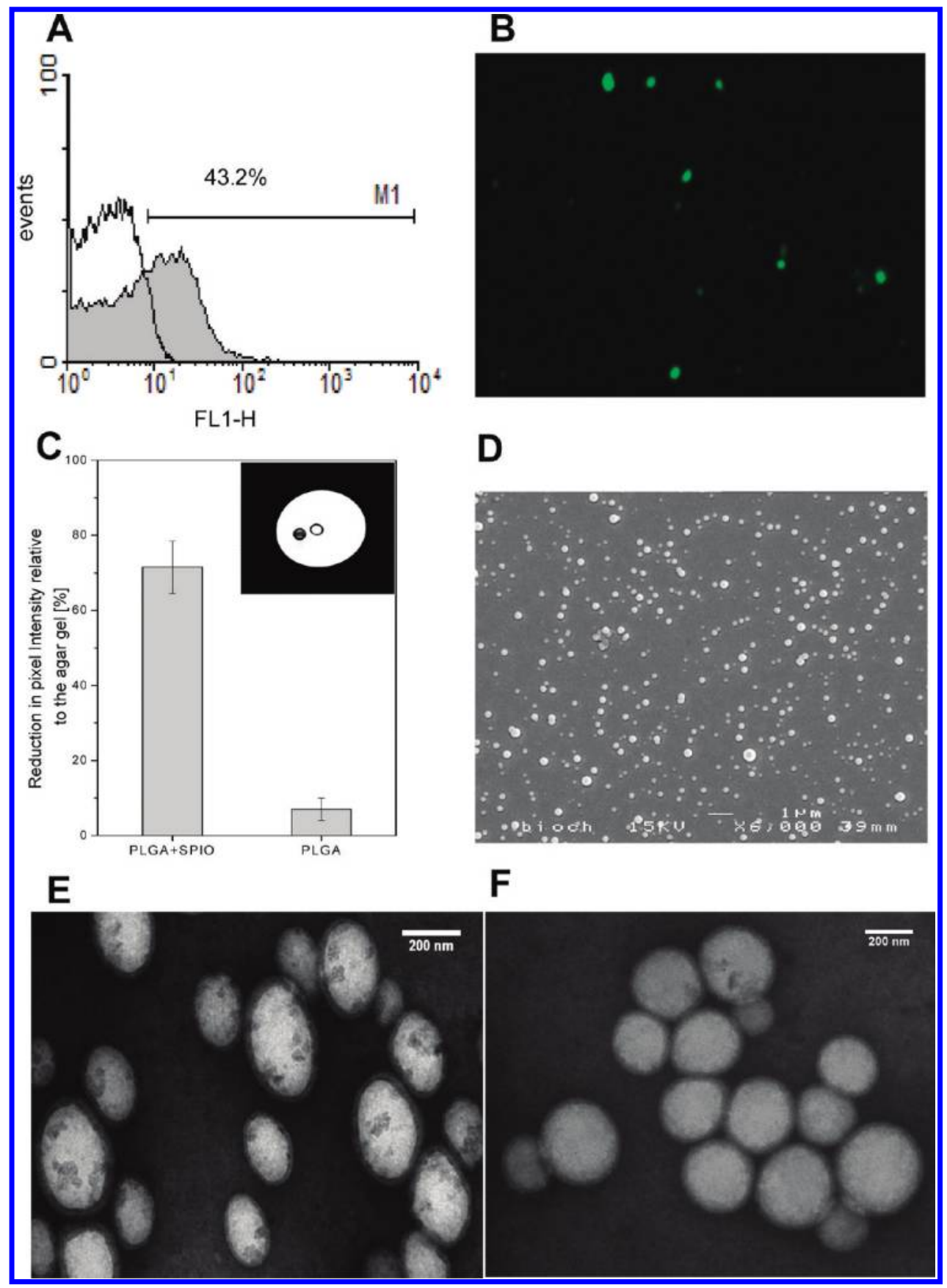

Figure 2. Nanovaccine carriers contain multimodal imaging properties. (A) The presence of FITC-TT peptide in the nanovaccine carriers was confirmed by measuring NPs with (gray, filled) or without (black line) encapsulated FITC-TT peptide by flow cytometry. (B) NPs containing FITCTT-SPIO nanoparticles were mounted on glass slides and visualized by confocal laser scanning microscopy. (C) The presence of SPIO inNPs was confirmed by MRI. The average signal intensity of capillary tubes containing SPIO-labeled NPs (left in the inset image) and NPs without SPIO (right in the inset image) was determined. A clear reduction in signal intensity was obtained for NPs when SPIO was encapsulated. (D) NP analysis by SEM revealed nanosized spherical particles. TEM analysis of NPs (E) with and (F) without SPIO. Image analysis revealed the electron-dense SPIO particles within the PLGA matrix of the NPs and the presence of the PEG-lipid layer surrounding the particles. (Scale bar, $200 \mathrm{~nm}$; magnification, $40000 \times$.)

2.8. Trasmission Electron Microscopy (TEM). Drops of NPs and NP-SPIO were deposited over carbon-coated Formvar films on copper grids and stained with a conventional negative staining for TEM using $2 \%$ uranyl acetate. Samples were analyzed with a transmission electron microscope (JEOL JEM 1010 (Jeol, Akishima Tokyo, Japan) at an accelerating voltage of $80 \mathrm{kV}$. The images were obtained with a CCD Megaview III (SIS) camera (Münster, Germany).
2.9. Dynamic Light Scattering and Zeta Potential. Dynamic light scattering (DLS) measurements on NPs were performed on an ALV light-scattering instrument equipped with an ALV5000/ $60 \times 0$ Multiple Tau Correlator and an Oxxius SLIM-532 150 $\mathrm{mW}$ DPSS laser operated at a wavelength of $532 \mathrm{~nm}$. A refractive index matching bath of filtered cis-decalin surrounded the cylindrical scattering cell, and the temperature was controlled at $21.5 \pm 0.3{ }^{\circ} \mathrm{C}$ using a Haake F3-K thermostat. For each sample 


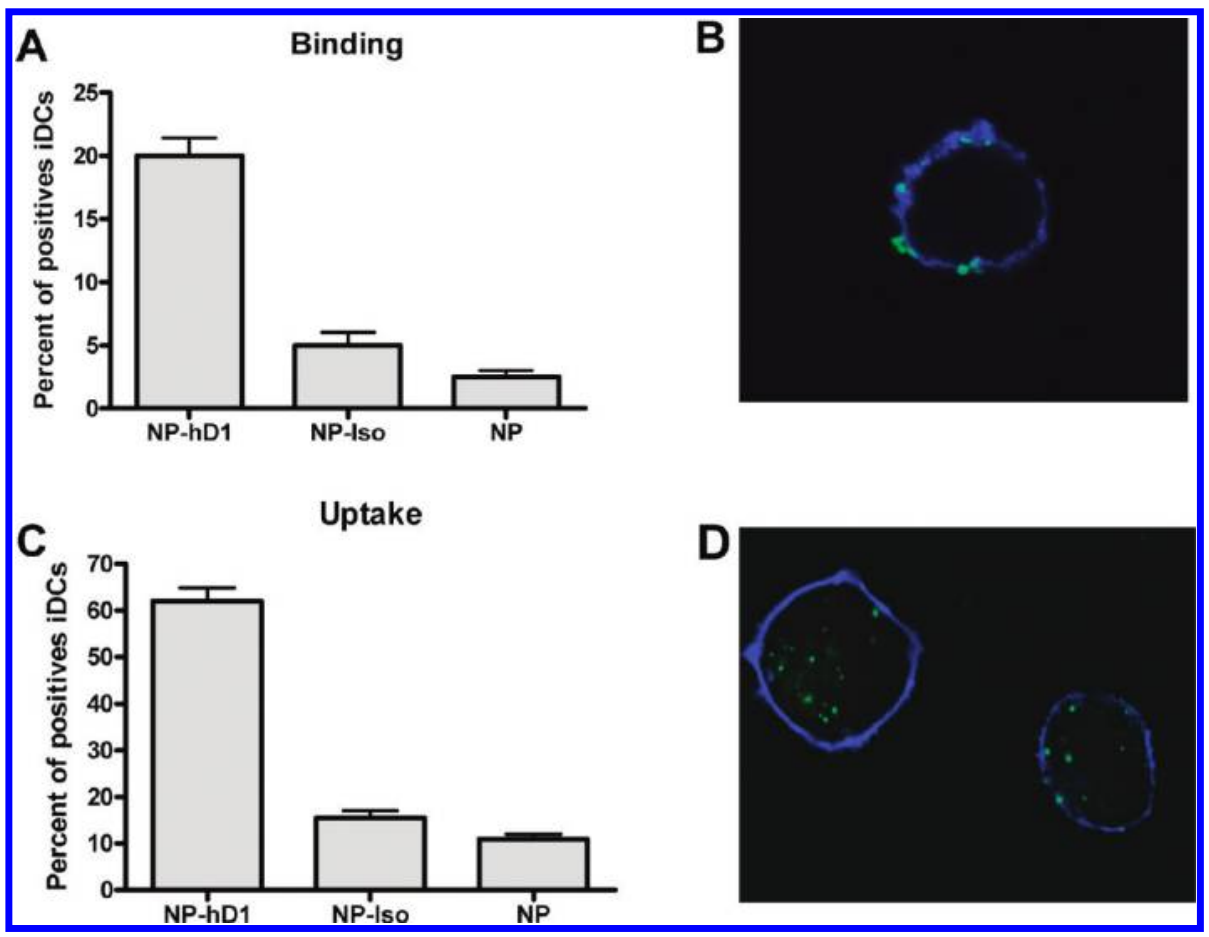

Figure 3. Analyzing nanovaccine carrier uptake and binding by fluorescence. Binding of various nanovaccine carriers were determined by (A) flow cytometry and (B) confocal microscopy. NP-hD1, NP-iso and NPs without Abs were incubated with DCs for $1 \mathrm{~h}$ at $4{ }^{\circ} \mathrm{C}$. DCs cultured in medium without NPs were included as a negative control. Part of the cells were analyzed by flow cytometry. The remaining cells were mounted on glass slides, and the cell membrane was stained with an antibody recognizing MHC class II. Cells were analyzed by confocal scanning laser microscopy to visualize binding of NP-hD1 to DCs. Subsequently, the experiments were repeated at $37^{\circ} \mathrm{C}$ to study NP uptake by DCs for $1 \mathrm{~h}$ using (C) flow cytometry and (D) confocal analysis. Flow cytometry data represent the mean of experiments performed in triplicate $\pm \mathrm{SD}$.

the autocorrelation function, $g_{2}(\tau)$, was recorded ten times at a detection angle of $90^{\circ}$. For each measurement the diffusion coefficient, $D$, was determined using the second order cumulant and the corresponding particle diameter was calculated assuming that the particles were spherical in shape. Zeta potential of NPs was determined on a Malvern ZetaSizer 2000 (U.K.).

2.10. Iron Staining of SPIO within DCs. After incubation of DCs with NPs-hD1 or NPs-isotype for $24 \mathrm{~h}$, cytospins of these cells were prepared and air-dried. Prussian blue staining was performed to detect SPIO within these cells. Slides were stained with freshly prepared potassium hexacyanoferrate(II) solution (Sigma, Germany; 2\%, with $0.1 \mathrm{~N} \mathrm{HCl}$ ) for $20 \mathrm{~min}$ and washed three times in distilled water. Slides were counterstained with $0.05 \%$ nuclear fast red in $5 \%$ aluminum sulfate. The samples were viewed in a Leica DMLB microscope.

2.11. Cells. Granulocytes and peripheral blood mononuclear cells (PBMCs) were obtained from buffy coats of healthy individuals and were purified using Ficoll density centrifugation. Peripheral blood lymphocytes (PBLs) and immature DCs (iDCs) were obtained from PBMCs as reported elsewhere. ${ }^{26}$ In brief, PBMCs were allowed to adhere for $1 \mathrm{~h}$ at $37^{\circ} \mathrm{C}$. Nonadherent cells (PBLs) were gently removed, washed and cryopreserved. Adherent monocytes were cultured in the presence of IL-4 and GM-CSF (500 and $800 \mathrm{U} / \mathrm{mL}$, respectively; Schering-Plough International, USA) for 6 days to obtain immature DCs. DCs were cryopreserved until use. Cells were cultured in X-VIVO 15 medium (Cambrex, Belgium) supplemented with $2 \%$ human serum.

2.12. Analysis of Uptake and Binding of NP by DCs Using Flow Cytometry. NP binding was studied by incubating cells with $20 \mu \mathrm{g} / \mathrm{mL} \mathrm{NP}-\mathrm{hD} 1$, isotype, or NPs without Abs for $1 \mathrm{~h}$ at $4{ }^{\circ} \mathrm{C}$ in culture medium. Subsequently, cells were washed and analyzed by flow cytometry. Uptake was studied by incubating cells with $20 \mu \mathrm{g} / \mathrm{mL} \mathrm{NP-hD1}$, isotype and NPs without Abs at $37{ }^{\circ} \mathrm{C}$ for $1 \mathrm{~h}$. The cells were washed and analyzed by flow cytometry on a FacsCalibur (Becton Dickinson, USA).

2.13. Analysis of Uptake and Binding of NP by DCs Using Confocal Microscopy. Binding and internalization of NPs containing FITC-TT was confirmed by confocal microscopy. Experiments were performed as described above for analyzing binding and uptake by flow cytometry. Subsequently, cells were fixed on poly-L-lysine coated glass slides and stained with antihuman MHC class II antibody (clone Q5/13) or IgG2a isotype control, followed by a secondary mAb goat-anti-mouse Alexa 647 antibody. Cells were imaged with a Bio-Rad MRC 1024 confocal system operating on a Nikon Optiphot microscope and a Nikon $60 \times$ planApo 1.4 oil immersion lenses. Pictures were analyzed with Bio-Rad Lasersharp 2000 and Adobe Photoshop 7.0 (Adobe Systems, USA) software.

2.14. Targeting NPs to DCs within a Mixed Blood Cell Population. Leukocytes isolated from buffy coats were mixed with DCs in a 20:1 ratio in culture medium. Cells were incubated with NPs-hD1, isotype, and NPs without Abs $(50 \mu \mathrm{g} / \mathrm{mL})$ at $37^{\circ} \mathrm{C}$ for $3 \mathrm{~h}$. Cells were washed and stained with a mannose receptor-specific antibody (clone 19.2, Becton Dickinson) or isotype control antibody to specifically detect DCs. Subsequently, cells were analyzed by flow cytometry on a FacsCalibur. The cell associated fluorescence was calculated by dividing the mean cell fluorescence intensity $(\mathrm{mfi})$ for a given sample by the mfi of DCs incubated with NP-hD1, which was set at $100 \%$. 


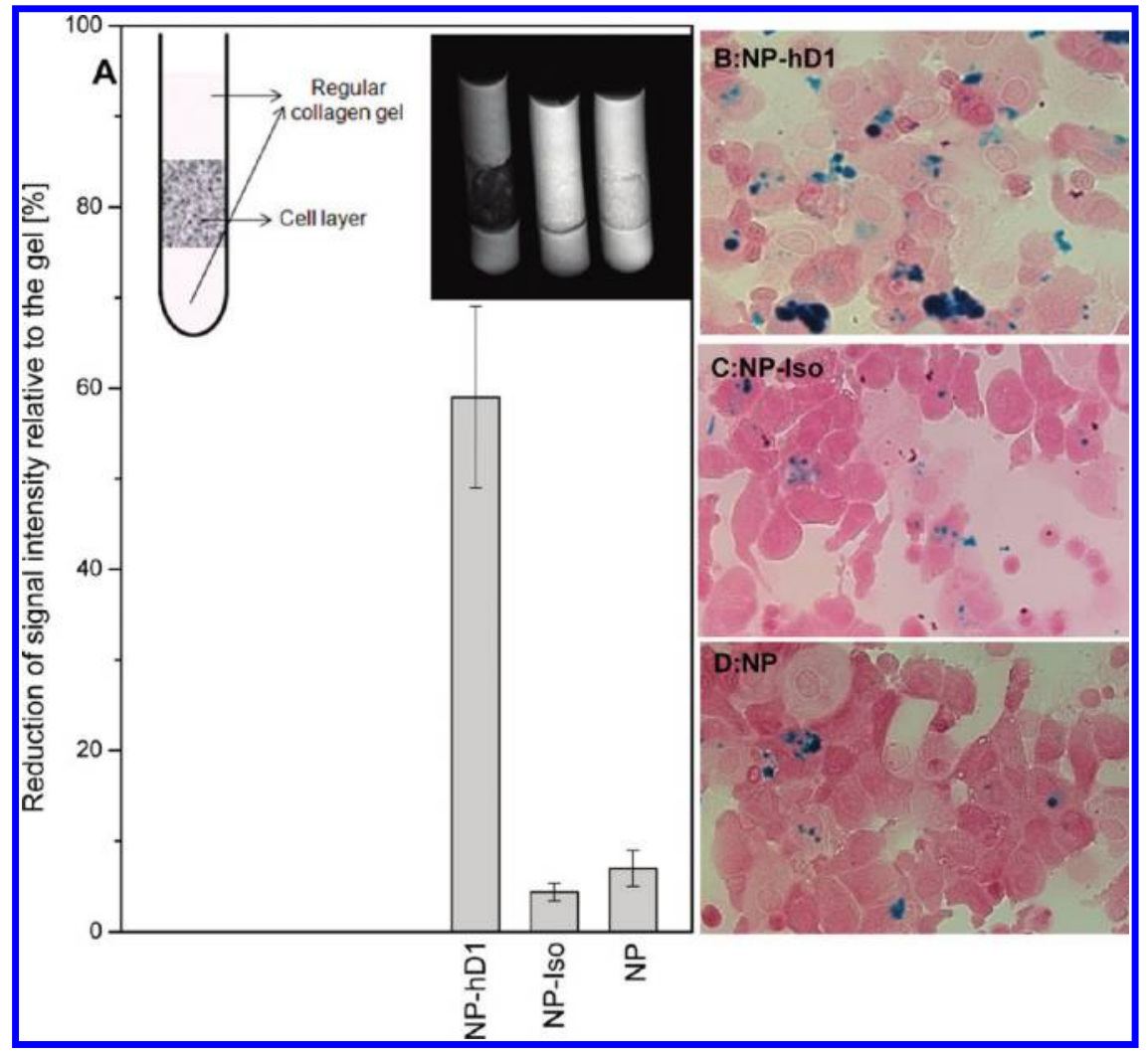

Figure 4. Detecting nanovaccine carrier uptake by DCs using MRI and Prussian blue staining. (A) Since fluorescent labels are rapidly exported out of the cell, prolonged uptake of NPs by DCs was analyzed by MRI. DCs were incubated with NP-hD1, NP-iso and NPs without Abs for $24 \mathrm{~h}$ at $37^{\circ} \mathrm{C}$ to study uptake by DCs. Subsequently, cells were embedded in collagen and placed in NMR tubes. Collagen gel without cells were positioned above and below the cells as a positive reference. Inset shows the MR image of the three collagen gels containing cells loaded with the various NPs. Relative SPIO content of the different samples was determined by measuring the average signal intensities of the reference gels and gels containing the DCs. The data represent mean values of an experiment performed in triplicate \pm SD. Histological analysis of DCs incubated with (B) NP-hd1, (C) NP-iso, and (D) NPs without Abs for $24 \mathrm{~h}$ at $37^{\circ} \mathrm{C}$. Cells were stained with Prussian blue staining to detect SPIO (blue). Cell nuclei are stained red. Magnification, $60 \times$.

2.15. Localization of Targeted NPs within DCs by TEM. The DCs were incubated with NPs-hD1, isotype or without Abs for $24 \mathrm{~h}$ and fixated with $2 \%$ glutaraldehyde $/ 0.1 \mathrm{~mol} / \mathrm{L}$ sodium cacodylate buffer ( $\mathrm{pH}$ 7.3). Then, the cells were rinsed in 0.1 $\mathrm{mol} / \mathrm{L}$ sodium cacodylate buffer, postfixed in $1 \% \mathrm{OsO} 4 / 0.1$ $\mathrm{mol} / \mathrm{L}$ sodium cacodylate buffer, rinsed in $0.1 \mathrm{~mol} / \mathrm{L}$ sodium cacodylate buffer and spun down in $2 \%$ agar $/ 0.1 \mathrm{~mol} / \mathrm{L}$ sodium cacodylate buffer. The cell pellet was cut in small cubes, dehydrated through graded alcohol and embedded in Agar 100 resin (Agar Scientific Limited, England).

Ultrathin sections were cut on a Leica Reichert Ultracut S picked up on Formvar coated copper grids, contrasted with uranyl acetate and lead citrate and examined with a Jeol 1010 transmission electron microscope (Jeol, Akishima Tokyo, Japan). Images were taken on Imaging plates (Ditabis) or with a CCD Megaview III (SIS) camera (Münster, Germany).

2.16. Characterization of SPIO-Containing NPs by MRI. The presence of SPIO presence inside NPs was analyzed by MRI. A fixed amount $(1 \mathrm{mg})$ of unlabeled and SPIO labeled NPs were embedded into $100 \mu \mathrm{L}$ of agar gel to produce a homogeneous sample. Each sample was introduced in capillary tubes, and both tubes were inserted into a $2 \mathrm{~mL}$ Eppendorf tube previously filled with agar gel. The whole sample was imaged in a 7T Clinscan MRI scanner (Bruker Biospin MRI GmbH, Germany) with a proton birdcage volume coil. The sample was placed inside the coil and a turbo spin echo pulse sequence $(\mathrm{TE} / \mathrm{TR}=7.7 / 900 \mathrm{~ms}$,
$0.12 \times 0.12 \times 1 \mathrm{~mm}$ resolution, turbo factor $=10)$ was used to obtain images.

2.17. Analysis of Uptake of Targeted NPs by DCs Using MRI. To analyze the uptake of vaccine carriers by DCs, $5 \times 10^{5}$ DCs were incubated with targeted and untargeted NPs containing identical amounts of SPIO for $24 \mathrm{~h}$ at $37{ }^{\circ} \mathrm{C}$ in culture medium. Subsequently, cells were embedded in $200 \mu \mathrm{L}$ of a collagen matrix and placed in NMR tubes. Collagen gels were placed above and below the cells as a positive reference. A turbo spin echo image $(\mathrm{TE} / \mathrm{TR}=4.2 / 900 \mathrm{~ms}, 0.1 \times 0.1$ in plane resolution, slice thickness $=5 \mathrm{~mm}$, turbo factor $=10$ ) was taken to directly compare the uptake of the three different carriers.

2.18. MRI Migration Experiment. A particular type of phantom was used to study cell migration. Gel scaffolds that mimic human tissue were specially prepared to track migration of hDCs labeled with NP-SPIO-hD1. In the bottom of a $2 \mathrm{~mL}$ Eppendorf tube, a $300 \mu \mathrm{L}$ scaffold layer was inserted as a control and in order to provide a flat surface for the cell layer. Right above this layer, $3 \times 10^{6}$ cells embedded in $200 \mu \mathrm{L}$ of scaffold gel layer was placed. On top of this (potential migration region), two $150 \mu \mathrm{L}$ layers with different CCL21 chemokine concentrations ( $40 \mathrm{nmol} / \mathrm{L}$ first layer, $80 \mathrm{nmol} / \mathrm{L}$ upper layer) were introduced in order to externally create a chemokine gradient to stimulate cell migration. Immediately after the whole sample was settled, the phantom was taken to the 7T MRI scanner to perform a longitudinal track of the cell migration. Ten consecutive and 


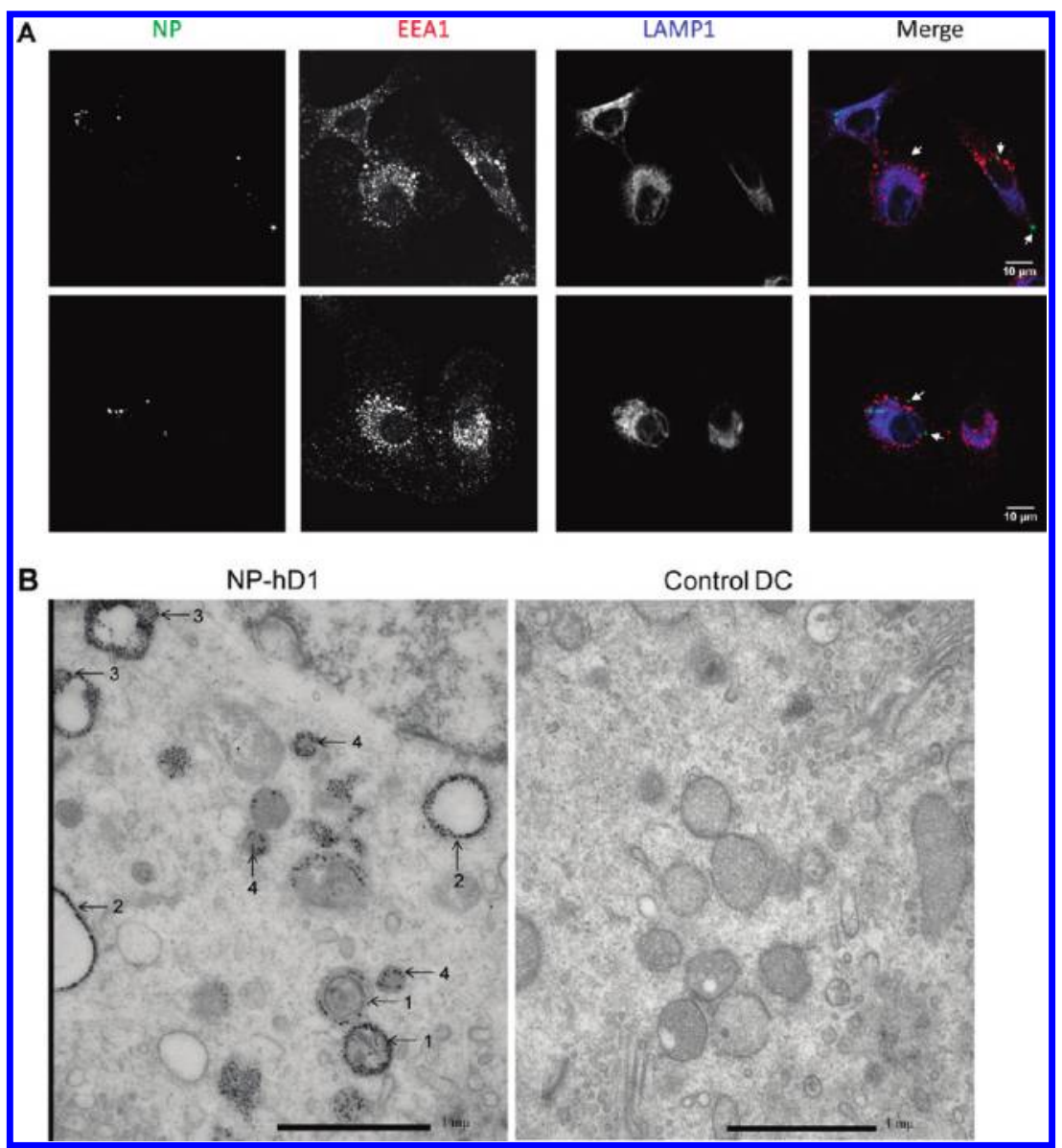

Figure 5. Subcellular tracking of nanovaccine carriers by confocal imaging and TEM. DCs were incubated with targeted nanovaccine (NP-hD1) for $1 \mathrm{~h}$ and chased for $24 \mathrm{~h}$. Subsequently, cells were fixed and analyzed by (A) confocal laser scanning microscopy or (B) TEM. For confocal laser scanning miscroscopy, DCs were stained for the early endosomal marker EEA1 and the lysosomal marker LAMP1. Following $24 \mathrm{~h}$ incubation fluorescence was still present in cells and mainly localized in the perinuclear area together with LAMP1. Part of the fluorescence also localized to EEA1 and LAMP1 negative sites suggesting targeted nanovaccine may escape from endosomes (arrows). For TEM studies DCs were embedded and analyzed. The NPs could be distinguished by their morphology from intracellular organelles. Part of the NPs was found in the endocytic vesicles (1). A proportion of the SPIO was already released from NPs and associated with endosomal or lysosomal membranes (2). Some NPs also appeared to be localized close to, or within, the vesicle membrane at the endosomal/cytosolic interface (3); other NPs were localized within the cytoplasm (4).

equivalent gradient echo images $(\mathrm{TE} / \mathrm{TR}=4 / 100 \mathrm{~ms}$; flip angle, $25^{\circ}$; in plane resolution, $0.16 \times 0.16 \mathrm{~mm}^{2}$; slice thickness, $\left.1 \mathrm{~mm}\right)$ were taken every $80 \mathrm{~min}$ to track potential migration of hDCs during $13 \mathrm{~h}$ approximately.

2.19. Antigen Presentation Assay. iDCs and PBLs of donors that respond to TT-antigen were obtained from buffy coats after informed consent. iDCs were incubated with NP-hD1 and isotype (containing $25 \mathrm{ng}$ to $1 \mathrm{ng}$ of FITC-TT peptide) for 2 days at $37^{\circ} \mathrm{C}$. Following washing, the TT-responsive PBLs were added to the iDCs $(1: 10 \mathrm{hDC} / \mathrm{T}$ cells relationship). Four days after addition of the PBLs, proliferative responses were determined by adding tritiated thymidine $(1 \mu \mathrm{Ci}[0.037 \mathrm{MBq}] /$ well; MP Biomedicals, Amsterdam, The Netherlands) to the cell cultures. Tritiated thymidine incorporation was measured after $16 \mathrm{~h}$ in a scintillation counter.

\section{RESULTS AND DISCUSSION}

3.1. Design, Preparation and Characterization of Targeted Nanovaccine. To design a NP to monitor DC-based vaccination strategies on subcellular, cellular and organism level we generated
NPs containing an optical imaging and a MRI contrast agent together with antigen. These particles were coated with a DCspecific antibody to specifically and efficiently load DCs (Figure 1). The tetanus toxoid (TT) 830-844 peptide was used as a clinically relevant model antigen to study presentation of nanovaccine-encapsulated antigens. This TT peptide is frequently used as a helper epitope in clinical trials to increase immune responses by increasing CD4 T cell response. ${ }^{33}$ In our case, the TT peptide was covalently linked to the fluorophore, FITC (FITC-TT), by continuous solid-phase synthesis, ${ }^{34}$ to allow visualization of incorporated peptide and uptake of PLGA containing FITC-TT peptide by DCs. The FITC label was separated from the TT peptide by a cleavage site (-KK-) that is recognized by the phagosomal/endosomal protease cathepsin, allowing peptides to be independently processed for presentation to T cells following NP ingestion. ${ }^{34,35}$

Furthermore we exploited superparamagnetic SPIO nanoparticles (see Table 1 in the Supporting Information). Initially, SPIO nanoparticles of $8.2 \pm 1.5 \mathrm{~nm}$ in diameter were conjugated to the peptide via a cleavable linker (-KK-) via an amide bond to allow separation of the peptide from the SPIO following uptake by 


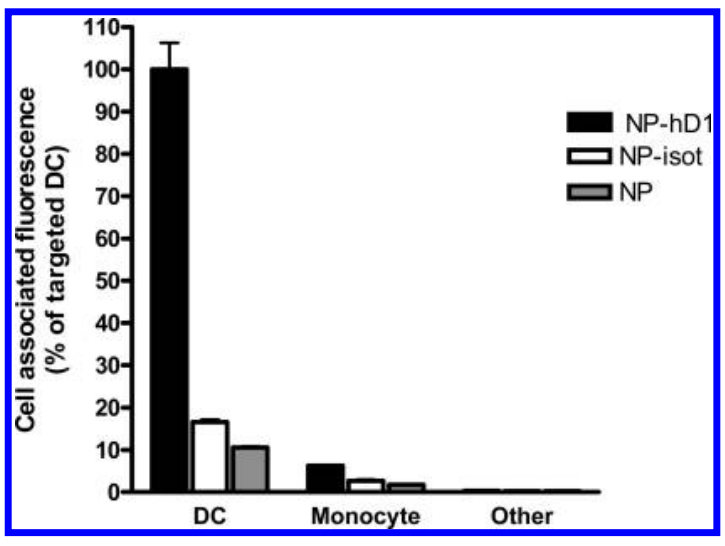

Figure 6. Specific interactions of targeted nanovaccine with human DCs within the whole blood cell population. The various nanovaccines were incubated with leukocytes and DCs to study selective interactions with human DCs. Leukocytes and DCs were mixed (ratio 20:1) and cultured for $2 \mathrm{~h}$ at $37^{\circ} \mathrm{C}$ in the presence of NP-hD1 (black bars), NP-iso (white bars) or NPs without Abs (gray bars) to study whether DCs are specifically targeted within a mixed blood cell population. DCs were detected by staining cells for mannose receptor expression. The relative fluorescence of the mannose receptor positive (DC) and negative (leukocytes) cells were calculated relative to the mean cell fluorescence of DCs incubated with NP-hD1, which were set at $100 \%$. Data are mean values \pm SD of experiments performed in duplicate.

cells. The conjugation of FITC-TT peptide to SPIO was confirmed by measuring particle-associated fluorescence. A similar strategy was successfully performed previously by Huang et al. to conjugate protein to SPIO. ${ }^{36}$ Next, FITC-TT-SPIO was encapsulated within the PLGA NPs using a single emulsion method. The loading efficiency of the SPIO in the PLGA NP was around $58 \%$. The NP surface was coated with a polyethylene glycol (PEG)-lipid layer to minimize nonspecific binding to cells and to allow the incorporation of a DC-specific anti-DC-SIGN (hD1) antibody to effectively target DCs. To facilitate both steps, a combination of unmodified and PEG-lipids functionalized with carboxyl groups was introduced on the NP surface. The characteristics of targeted PLGA NPs containing SPIO and FITC-TT peptide (size distribution, polydispersity index, zeta potential, FITC-TT entrapment efficiency, SPIO content and amount of Abs conjugated to PLGA nanoparticle surface) are shown in Table 1. Exploiting dynamic light scattering (DLS) to assess the difference in size between NPs with and without Abs attached to the surface, we found that PLGA-NPs without Abs was 199.4 \pm $3.4 \mathrm{~nm}$ in diameter, while the sizes of NP-hD1 and isotype were $225.6 \pm 12.6$ and $227.8 \pm 11.2 \mathrm{~nm}$, respectively. It should be noted that the conjugation of Abs to the NP alters the size. The hydrodynamic diameter of the NP increases approximately in 26.2 and $28.4 \mathrm{~nm}$ respectively, when the $\mathrm{Abs}$ ( $\mathrm{hD} 1$ and isotype) were incorporated on the PLGA surface. This increase is in agreement with the theoretical length of Abs, which is about $13.5 \pm 1.5 \mathrm{~nm}$. Flow cytometry confirmed that antibodies were present on the surface (see Supporting Information, Figure S1). In addition, the zeta potential of antibody-coated NPs was considerably less negative than the NPs without Abs (Table 1). The zeta potential value of noncoated NP-COOH was $-34.9 \pm$ $3.6 \mathrm{mV}$ while the values of $\mathrm{NP}-\mathrm{hD} 1$ and isotype were $-14.5 \pm$ 4.6 and $-12.7 \pm 3.5 \mathrm{mV}$, respectively. This reduction in the zeta potential reflects the conjugation reaction between the carboxyl group of NPs and the amino groups of the Abs, providing

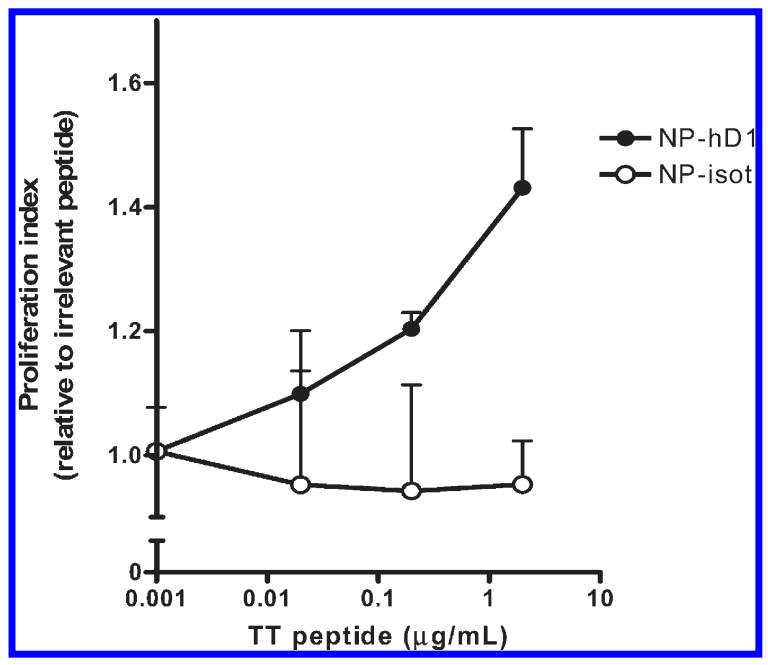

Figure 7. Specific targeting of nanovaccine to human DCs enhances antigen presentation. Presentation of TT peptide was studied by culturing DCs for 2 days in medium with or without addition of various concentrations of NP-hD1 (closed circles) or NP-isot (open circles). Subsequently, autologous TT-responsive PBLs were added. After 4 days, cellular responses were assessed in a proliferation assay. Data are mean proliferation indices $\pm S D$ relative to medium control for three experiments.

additional evidence that the Abs were present on the NP surface. Therefore, conjugation of Abs to NPs alters not only their size but also particle charge. The amount of antibodies present on the particle surface was $18.1 \pm 1.5 \mu \mathrm{g}$ per mg of PLGA for hD1 and $19.3 \pm 1.8 \mu \mathrm{g}$ per mg of PLGA for the isotype control antibody, as determined by a Coomassie-based protein assay (see Table 1). All NPs showed a relatively uniform size distribution, which was reflected by low polydispersity indexes $(0.117 \pm 0.056$ and $0.197 \pm 0.066$, respectively).

3.2. Multimodal Imaging of NPs. To demonstrate that the NPs could be monitored at the subcellular, cellular and multicellular levels due to its multimodal imaging properties (fluorescence and magnetic resonance), a combination of various techniques were used. Flow cytometry and confocal imaging clearly showed the presence of FITC-TT peptide within NPs (Figure 2A,B), while the SPIO was detectable by MRI. Figure $2 \mathrm{C}$ shows the average signal intensity of unlabeled and SPIO-labeled NPs in the image shown in the inset. A significant decrease in the signal intensity (darkening of the image) was clearly appreciated in labeled NPs, confirming that SPIO were efficiently incorporated within PLGA. It is important to note that, even though turbo spin echo is one of the less sensitive MRI sequences to detect the presence of iron in water protons, the reduction in signal intensity was easily visualized. These findings indicate that NPs containing SPIO are suitable for noninvasive imaging monitor the distribution of injected NPs that target DCs in vivo, or to follow migration of ex vivo-loaded DCs after administration.

The multimodal imaging characteristics of the NPs shown in Figure 2 allow the integration of the advantages of MR and optical imaging techniques. The low sensitivity of MRI can be complemented by the sensitive optical imaging modality close to the external body surface, while noninvasive molecular imaging in the deep tissue can be obtained using MRI.

The morphology of the NPs was determined by scanning electron microscopy (SEM) (Figure 2D) and TEM (Figure 2E,F). 


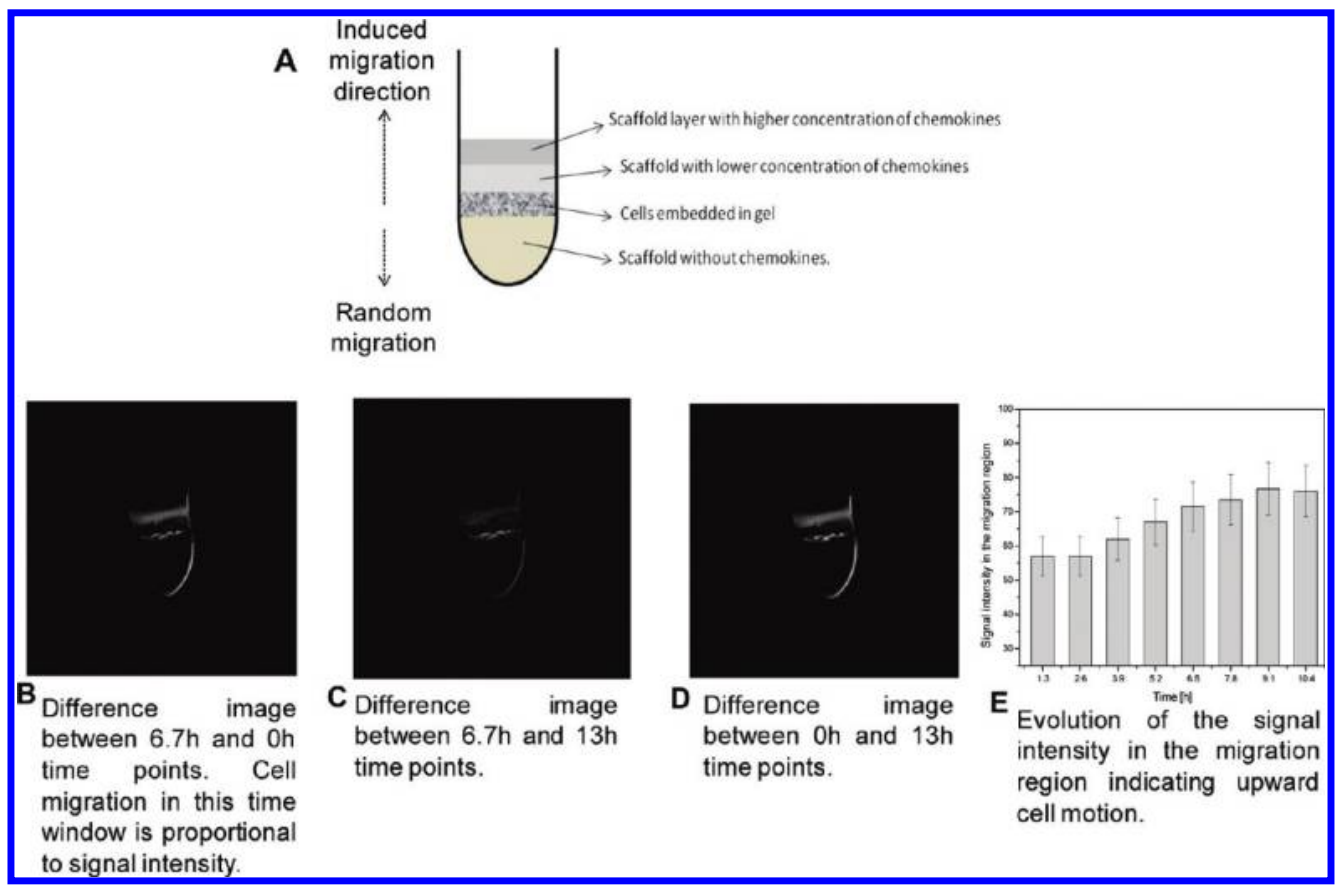

Figure 8. Tracking migration of nanovaccine-labeled human DCs in scaffolds. (A) Schematic overview of the experimental setup. Difference images between different time points are shown in (B) $0 \mathrm{~h}$ to $6.7 \mathrm{~h},(\mathrm{C}) 6.7 \mathrm{~h}$ to $13 \mathrm{~h}$, and (D) $0 \mathrm{~h}$ to $13 \mathrm{~h}$. The upper brighter horizontal bands in these images clearly reveal upward migration. (E) The average signal intensity in the migration region was determined at various time points. Data are mean signal intensity \pm SD for two experiments.

This showed that the NPs were spherical in shape, while TEM analysis revealed the SPIO present within the particle (Figure 2E). In addition, TEM imaging revealed the presence of the PEG-lipid layer on the NPs.

3.3. Specific Binding and Uptake of the NPs by DC for ex Vivo Labeling. To demonstrate one of the advantages of using fluorescent imaging agents we used the fluorescent properties of our NPs to quantify specific binding and uptake following targeted delivery to DCs. NPs coated with $\mathrm{hD} 1$ antibody did bind to DCs, while NPs with isotype control or no antibodies did hardly bind (Figure 3A). Confocal microscopy confirmed that the NPs carrying $\mathrm{hD} 1$ antibody were attached to the cell membrane of DCs (Figure 3B). These data showed that targeted NPs mainly bind DCs via $\mathrm{DC}-\mathrm{SIGN}$ and not through nonspecific interactions resulting from the surface charge or $\mathrm{Fc}$ receptor binding.

The capacity of the DC-targeted NPs to deliver its contents inside the cell was investigated by flow cytometry, confocal imaging, Prussian blue staining and MRI. After $1 \mathrm{~h}$ at $37^{\circ} \mathrm{C}$, the uptake of NPs-hD1 (62\%) was higher than the corresponding NPs-isotype control antibody (15\%) or no antibody (11\%) according to FACS analysis (Figure 3C). These findings were confirmed by confocal imaging and showed that NPs were indeed internalized by the DC rather than simply binding the cell surface (Figure 3D).

The MR properties of our nanovaccines can be exploited for noninvasive imaging to monitor the migration of targeted DCs in vivo or ex vivo loaded. However, MRI sensitivity depends on the ability to label cells with sufficient quantities of SPIO to allow detection. To address this issue, we incubated human DCs for a prolonged period of time, $24 \mathrm{~h}$, with high concentrations of targeted and untargeted NPs. Differences in cellular uptake of the various NPs were measured by MRI and confirmed via Prussian blue staining. In line with the flow cytometry data obtained in the experiments shown in Figure 3C following $1 \mathrm{~h}$ of uptake, a significant increase in uptake of NPs-hD1 by DCs was also detected after $24 \mathrm{~h}$ when compared to uptake of isotype control NPs and noncoated NPs (Figure 4A). The average signal intensities for the different regions of the image (inset in Figure 4A) are shown.

The ability to detect SPIO-labeled DCs by histological analysis is important to visualize the intra lymph node or tissue localization of DCs following therapy and will, for example, allow us to assess whether DC-vaccines used in clinical trials are able to reach the $\mathrm{T}$ cell areas of the lymph node. ${ }^{37}$

Therefore, we assessed whether the presence of SPIO containing NPs could be detected in DCs by histological analysis using Prussian blue staining to detect iron. The DC were loaded with targeted and untargeted NPs and incubated during $24 \mathrm{~h}$. Prussian blue staining confirmed that NPs containing iron oxide nanoparticles were internalized by DCs (Figure 4B-D). In agreement with flow cytometry and MRI data DCs treated with NP-hD1 showed more intense staining for iron than DCs exposed to NPisotype and NPs without Abs.

In conclusion, the intracellular uptake of NPs was confirmed by confocal imaging and Prussian blue staining. Furthermore, uptake was evaluated semiquantitatively by flow cytometry and MRI. Consistent results were obtained by the various techniques, showing there was a significant increase in nanovaccine uptake by the DC-specific hD1 antibody.

3.4. Intracellular Localization Detected by Confocal Imaging and Transmission Electron Microscopy. Next, we exploited the multimodal properties of our NPs to track and localize their routing inside DCs. Adherent DCs were loaded with NPs for $1 \mathrm{~h}$ and incubated for another $24 \mathrm{~h}$. Subsequently, DCs were stained for the early endosomal marker EEA1 and the late endosomal/lysosomal marker LAMP1 to visualize the various components of the endosomal system (Figure 5A). 
NP-derived fluorescence did not colocalize with EEA1 but partly overlapped with LAMP1 positive compartments indicating that NPs reached the site where degraded antigens are loaded onto major histocompatibility class II for presentation. However, part of the fluorescence localized neither to EEA1 nor to LAMP1 positive compartments. This could indicate that some particles escaped from the endosomal pathway. Indeed, it was suggested before those PLGA particles are able to cross the endosomal membrane and deliver encapsulated antigen into the cytoplasm. ${ }^{38,39}$

Additional information about the intracellular fate of the NPs was obtained by electron microscopy, using the encapsulated iron as a contrast agent. Electron dense SPIO structures could be seen in DCs exposed to NP-hD1 and not in control DCs, showing PLGA is detected by TEM (Figure 5B). SPIO appeared more electron dense than PLGA and could be detected within PLGA NP structures. Intact NPs containing SPIO and that were not obviously surrounded by an additional bilayer other than the one representing the PEG layer were detected in the cytosol of DCs. This suggests that part of the NPs escaped from endosomal compartments. ${ }^{38}$ In addition, some NPs were localized within endosomal structures. Unexpectedly, we also detected some free SPIO associated with endosomal membranes, suggesting SPIO had already been released from the carrier and preferentially associated with membrane structures.

Taken together, by using confocal imaging and TEM, it was possible to demonstrate that targeted SPIO and FITC labeled NPs are internalized into endosomal compartments within DCs. Whereas confocal analysis was useful to identify the nature of the endosomal compartments containing the fluorescent vaccine, TEM suggested that part of the vaccine carriers had escaped into the cytosol. The results also showed that $24 \mathrm{~h}$ after particle uptake some SPIO had already been released, while the rest remained within the carrier, which is in agreement with the slow degradation process of the PLGA polymer. ${ }^{40}$ These slow release characteristics should be favorable for both antigen presentation and the ability to track DCs by MRI over a prolonged period of time.

3.5. Determining Specificity of Targeted NPs for DCs. To further explore the efficiency of targeted delivery of our vaccine carrier in a more complex system we used the fluorescent properties of NPs to determine the specificity by which NPs were taken up by DCs and other cells. To mimic the situation when targeted NPs are injected into the bloodstream, we determined the effectiveness of targeting NPs to DCs within a mixed blood cell population. Monocyte-derived human DCs were added to leukocytes isolated from whole blood in a ratio of 1:20. NPs targeted to DC-SIGN were more effectively internalized by DCs than untargeted controls (Figure 6). These results showed that NPs by themselves passively target to DCs, which is enhanced by engrafting DC-specific antibodies on the particle surface.

3.6. Fluorophore-Peptide Antigen Conjugate Is Processed by DCs and Presented to T Cells. Antigen presentation studies were performed to determine whether the multimodal imaging strategy was compatible with antigen presentation. DCs from donors that respond to TT-antigen were exposed to targeted and untargeted NPs and incubated with autologous T cells. Despite the presence of SPIO and the fact that FITC was linked to the peptide antigen, DCs were capable of presenting the encapsulated antigen to $\mathrm{T}$ cells, resulting in $\mathrm{T}$ cell proliferation (Figure 7). Particles coated with $\mathrm{hD} 1$ induced $\mathrm{T}$ cell proliferation in a dose dependent fashion, whereas the isotype control coated
NPs did not induce $\mathrm{T}$ cell proliferation at the tested concentrations. These results are in agreement with our previous data, showing enhanced antigen presentation following targeted delivery of antigen to DC-SIGN. ${ }^{31}$

3.7. MRI Tracking of DC Migration. Finally, to evaluate the migration and tracking of human DCs loaded with NP-hD1, collagen scaffolds were used to mimic human tissue. The experimental setup is schematically plotted in Figure 8A. In the bottom part of a $2 \mathrm{~mL}$ eppendorf tube, a scaffold layer was inserted to provide a flat surface onto which DCs embedded in a second scaffold gel layer were placed. Above the DC layer, the potential migration region was applied, consisting of two layers with different chemokine concentrations. This setup should generate a gradient triggering DC migration in the direction of the chemokine. Immediately after the whole sample was settled, the tube was analyzed in a 7T MRI scanner to longitudinally track cell migration. Ten consecutive and equivalent gradient echo images were taken every 80 min to track DC migration for $13 \mathrm{~h}$.

Figures $8 \mathrm{~B}-\mathrm{D}$ show the difference images $(1 \mathrm{st}-5$ th, 5th -10 th, and 1st-10th) corresponding to $0 \mathrm{~h}$ to $6.7 \mathrm{~h}, 6.7 \mathrm{~h}$ to $13 \mathrm{~h}$, and $0 \mathrm{~h}$ to $13 \mathrm{~h}$ time windows. These images were generated in order to readily visualize relocalization of the contrast agent within the collagen scaffold. The migration region can easily be distinguished as a thick band in the upper part of the sample. The very intense and thin line below the migration region corresponds to random susceptibility artifacts typical of regions with high density of SPIO particles. A signal increase with time in the migration region clearly indicates that DCs had migrated upward.

Figure $8 \mathrm{E}$ shows the evolution of the signal intensity in the migration region during the whole experiment. The data clearly show that DCs migrated toward regions containing high chemokine levels. Migration was more pronounced during the first part of the experiment, then decreased and eventually stopped. This is possibly related to cell death during the experiment due to factors such as lack of oxygen and nutrients and changes in temperature.

Two conclusions can be drawn from this experiment. First, ex vivo cultured human DCs were efficiently labeled with our targeted multimodal NPs and allowed tracking of cell migration. Second, the NPs did not abolish DC migration toward chemokines, which is important for DC migration toward the lymph nodes where they present antigen to $\mathrm{T}$ cells and induce immune responses.

\section{CONCLUSIONS}

We developed a nanovaccine consisting of a biocompatible polymer containing SPIO and FITC-labeled peptide antigen as a multimodal imaging contrast agent. We demonstrated that SPIO was successfully encapsulated within our targeted NPs, confirming the results of a recent study by Lee and co-workers showing successful entrapment of SPIO within PLGA. ${ }^{41}$ Coating NPs with DC-specific DC-SIGN Abs significantly increased SPIO uptake as compared to untargeted controls in vitro. At the same time, the fluorophore allowed quantitative analysis of binding and internalization by cells by flow cytometry and allowed identification of the endosomal compartments containing the vaccine by confocal analysis. SPIO was useful for tracking NP uptake and migration of DCs by MRI in a 3D context as an artificial tissue. Together, this identifies PLGA NPs as biocompatible vaccine carriers that allow tracking by fluorescence and MRI without loss of vaccine function. As such, these targeted 
NPs constitute a valuable tool for optimizing DC-based vaccine therapeutics. These NPs could be used to track current DC vaccines based on cells that are loaded with antigen ex vivo following readministration into patients, but also to evaluate in vivo antibody-mediated DC targeting strategies in preclinical studies. The ability to track targeted NPs at the subcellular, cellular and organism level make it a valuable tool to study diverse processes such as receptor biology, antigen processing and presentation, biodistribution of targeted vaccines and DC migration. Thereby, these NPs open up novel possibilities in nanomedicine to design intelligent vaccines that enter the appropriate cellular compartment and induce DC activation and migration to prompt the most optimal immune response.

\section{ASSOCIATED CONTENT}

S Supporting Information. Additional table and figure as discussed in the text. This material is available free of charge via the Internet at http://pubs.acs.org.

\section{AUTHOR INFORMATION}

\section{Corresponding Author}

${ }^{*}$ Department of Tumor Immunology, Nijmegen Centre for Molecular Life Sciences, Radboud University Nijmegen Medical Centre, Postbox 9101, 6500 HB Nijmegen, The Netherlands. Fax: +31-24-3540339. Tel: +31-24-3617600. E-mail: c.figdor @ncmls.ru.nl.

\section{ACKNOWLEDGMENT}

The authors wish to thank the technicians of the NCMLS Tumor Immunology Department Clinical DC group for assistance. This work was supported by Marie Curie Research Training Network (RTN) Immunanomap.

\section{ABBREVIATIONS:}

Abs, antibodies; DC, dendritic cell; DIEA, N,N-diisopropylethylamine; DLS, dynamic light scattering; DMF, $N, N$-dimethylformamide; EDAC, $N$-(3-dimethylaminopropyl)- $N$-ethylcarbodiimide hydrochloride; FDA, food and drug administration; $\mathrm{HOBt}$, 1-hydroxybenzotriazole; NHS (N-hydroxisuccinimide)HPLC, high performance liquid chromatography; MALDI-TOF, matrix-assisted laser desorption ionization with time-of-flight analysis; NP, nanovaccine particle; PBL, peripheral blood lymphocyte; PBMC, peripheral blood mononuclear cell; PEG, polyethylene glycol; PVA, polyvinyl alcohol; RP, reverse phase; TFA, trifluoroacetic acid; TT, tetanus toxoid

\section{REFERENCES}

(1) Lesterhuis, W. J.; Aarntzen, E. H.; De Vries, I. J.; Schuurhuis, D. H.; Figdor, C. G.; Adema, G. J.; Punt, C. J. Dendritic cell vaccines in melanoma: from promise to proof? Crit. Rev. Oncol. Hematol. 2008, 66 (2), 118-34.

(2) Adema, G. J.; de Vries, I. J.; Punt, C. J.; Figdor, C. G. Migration of dendritic cell based cancer vaccines: in vivo veritas? Curr. Opin. Immunol. 2005, 17 (2), 170-4.

(3) Tacken, P. J.; de Vries, I. J.; Torensma, R.; Figdor, C. G. Dendritic-cell immunotherapy: from ex vivo loading to in vivo targeting. Nat. Rev. Immunol. 2007, 7 (10), 790-802.

(4) De Vries, I. J.; Krooshoop, D. J.; Scharenborg, N. M.; Lesterhuis, W. J.; Diepstra, J. H.; Van Muijen, G. N.; Strijk, S. P.; Ruers, T. J.;
Boerman, O. C.; Oyen, W. J.; Adema, G. J.; Punt, C. J.; Figdor, C. G. Effective migration of antigen-pulsed dendritic cells to lymph nodes in melanoma patients is determined by their maturation state. Cancer Res. 2003, 63 (1), 12-7.

(5) de Vries, I. J.; Lesterhuis, W. J.; Barentsz, J. O.; Verdijk, P.; van Krieken, J. H.; Boerman, O. C.; Oyen, W. J.; Bonenkamp, J. J.; Boezeman, J. B.; Adema, G. J.; Bulte, J. W.; Scheenen, T. W.; Punt, C. J.; Heerschap, A.; Figdor, C. G. Magnetic resonance tracking of dendritic cells in melanoma patients for monitoring of cellular therapy. Nat. Biotechnol. 2005, 23 (11), 1407-13.

(6) Olasz, E. B.; Lang, L.; Seidel, J.; Green, M. V.; Eckelman, W. C.; Katz, S. I. Fluorine-18 labeled mouse bone marrow-derived dendritic cells can be detected in vivo by high resolution projection imaging. J. Immunol. Methods 2002, 260 (1-2), 137-48.

(7) Schimmelpfennig, C. H.; Schulz, S.; Arber, C.; Baker, J.; Tarner, I.; McBride, J.; Contag, C. H.; Negrin, R. S. Ex vivo expanded dendritic cells home to T-cell zones of lymphoid organs and survive in vivo after allogeneic bone marrow transplantation. Am. J. Pathol. 2005, 167 (5), 1321-31.

(8) Baumjohann, D.; Hess, A.; Budinsky, L.; Brune, K.; Schuler, G.; Lutz, M. B. In vivo magnetic resonance imaging of dendritic cell migration into the draining lymph nodes of mice. Eur. J. Immunol. 2006, 36 (9), 2544-55.

(9) Verdijk, P.; Scheenen, T. W.; Lesterhuis, W. J.; Gambarota, G.; Veltien, A. A.; Walczak, P.; Scharenborg, N. M.; Bulte, J. W.; Punt, C. J.; Heerschap, A.; Figdor, C. G.; de Vries, I. J. Sensitivity of magnetic resonance imaging of dendritic cells for in vivo tracking of cellular cancer vaccines. Int. I. Cancer 2007, 120 (5), 978-84.

(10) Jain, T. K.; Richey, J.; Strand, M.; Leslie-Pelecky, D. L.; Flask, C. A.; Labhasetwar, V. Magnetic nanoparticles with dual functional properties: drug delivery and magnetic resonance imaging. Biomaterials 2008, 29 (29), 4012-21.

(11) Reichardt, W.; Durr, C.; von Elverfeldt, D.; Juttner, E.; Gerlach, U. V.; Yamada, M.; Smith, B.; Negrin, R. S.; Zeiser, R. Impact of mammalian target of rapamycin inhibition on lymphoid homing and tolerogenic function of nanoparticle-labeled dendritic cells following allogeneic hematopoietic cell transplantation. J. Immunol. 2008, 181 (7), 4770-9.

(12) Lim, Y. T.; Noh, Y. W.; Han, J. H.; Cai, Q. Y.; Yoon, K. H.; Chung, B. H. Biocompatible polymer-nanoparticle-based bimodal imaging contrast agents for the labeling and tracking of dendritic cells. Small 2008, 4 (10), 1640-5.

(13) Ngaboni Okassa, L.; Marchais, H.; Douziech-Eyrolles, L.; Cohen-Jonathan, S.; Souce, M.; Dubois, P.; Chourpa, I. Development and characterization of sub-micron poly(D,L-lactide-co-glycolide) particles loaded with magnetite/maghemite nanoparticles. Int. J. Pharm. 2005, 302 (1-2), 187-96.

(14) Okassa, L. N.; Marchais, H.; Douziech-Eyrolles, L.; Herve, K.; Cohen-Jonathan, S.; Munnier, E.; Souce, M.; Linassier, C.; Dubois, P.; Chourpa, I. Optimization of iron oxide nanoparticles encapsulation within poly(d,1-lactide-co-glycolide) sub-micron particles. Eur. J. Pharm. Biopharm. 2007, 67 (1), 31-8.

(15) Beaune, G.; Dubertret, B.; Clement, O.; Vayssettes, C.; Cabuil, V.; Menager, C. Giant vesicles containing magnetic nanoparticles and quantum dots: feasibility and tracking by fiber confocal fluorescence microscopy. Angew. Chem. Int. Ed. 2007, 46 (28), 5421-4.

(16) McCarthy, J. R.; Jaffer, F. A.; Weissleder, R. A macrophagetargeted theranostic nanoparticle for biomedical applications. Small 2006, 2 (8-9), 983-7.

(17) Mulder, W. J.; Griffioen, A. W.; Strijkers, G. J.; Cormode, D. P.; Nicolay, K.; Fayad, Z. A. Magnetic and fluorescent nanoparticles for multimodality imaging. Nanomedicine (London) 2007, 2 (3), 307-24.

(18) Uzgiris, E. E.; Sood, A.; Bove, K.; Grimmond, B.; Lee, D.; Lomnes, S. A multimodal contrast agent for preoperative MR Imaging and intraoperative tumor margin delineation. Technol. Cancer Res. Treat. 2006, 5 (4), 301-9.

(19) Veiseh, O.; Sun, C.; Gunn, J.; Kohler, N.; Gabikian, P.; Lee, D.; Bhattarai, N.; Ellenbogen, R.; Sze, R.; Hallahan, A.; Olson, J.; Zhang, M. 
Optical and MRI multifunctional nanoprobe for targeting gliomas. Nano Lett. 2005, 5 (6), 1003-8.

(20) Harisinghani, M. G.; Dixon, W. T.; Saksena, M. A.; Brachtel, E.; Blezek, D. J.; Dhawale, P. J.; Torabi, M.; Hahn, P. F. MR lymphangiography: imaging strategies to optimize the imaging of lymph nodes with ferumoxtran-10. Radiographics 2004, 24 (3), 867-78.

(21) Lu, C. W.; Hung, Y.; Hsiao, J. K.; Yao, M.; Chung, T. H.; Lin, Y. S.; Wu, S. H.; Hsu, S. C.; Liu, H. M.; Mou, C. Y.; Yang, C. S.; Huang, D. M.; Chen, Y. C. Bifunctional magnetic silica nanoparticles for highly efficient human stem cell labeling. Nano Lett. 2007, 7 (1), 149-54.

(22) O’Hagan, D. T.; Rahman, D.; McGee, J. P.; Jeffery, H.; Davies, M. C.; Williams, P.; Davis, S. S.; Challacombe, S. J. Biodegradable microparticles as controlled release antigen delivery systems. Immunology 1991, 73 (2), 239-42.

(23) Gupta, A. K.; Gupta, M. Cytotoxicity suppression and cellular uptake enhancement of surface modified magnetic nanoparticles. Biomaterials 2005, 26 (13), 1565-73.

(24) Martina, M. S.; Nicolas, V.; Wilhelm, C.; Menager, C.; Barratt, G.; Lesieur, S. The in vitro kinetics of the interactions between PEGylated magnetic-fluid-loaded liposomes and macrophages. Biomaterials 2007, 28 (28), 4143-53.

(25) Quaranta, V.; Walker, L. E.; Pellegrino, M. A.; Ferrone, S. Purification of immunologically functional subsets of human Ia-like antigens on a monoclonal antibody (Q5/13) immunoadsorbent. I. Immunol. 1980, 125 (4), 1421-5.

(26) Tacken, P. J.; de Vries, I. J.; Gijzen, K.; Joosten, B.; Wu, D.; Rother, R. P.; Faas, S. J.; Punt, C. J.; Torensma, R.; Adema, G. J.; Figdor, C. G. Effective induction of naive and recall $\mathrm{T}$-cell responses by targeting antigen to human dendritic cells via a humanized anti-DC-SIGN antibody. Blood 2005, 106 (4), 1278-85.

(27) Thomas, T. C.; Rollins, S. A.; Rother, R. P.; Giannoni, M. A.; Hartman, S. L.; Elliott, E. A.; Nye, S. H.; Matis, L. A.; Squinto, S. P.; Evans, M. J. Inhibition of complement activity by humanized anti-C5 antibody and single-chain Fv. Mol. Immunol. 1996, 33 (17-18), 1389-401.

(28) Houghten, R. A.; Bray, M. K.; Degraw, S. T.; Kirby, C. J. Simplified procedure for carrying out simultaneous multiple hydrogen fluoride cleavages of protected peptide resins. Int. J. Pept. Protein Res. 1986, 27 (6), 673-8.

(29) Kaiser, E.; Colescott, R. L.; Bossinger, C. D.; Cook, P. I. Color test for detection of free terminal amino groups in the solid-phase synthesis of peptides. Anal. Biochem. 1970, 34 (2), 595-8.

(30) Kumar, C. S.; Leuschner, C.; Doomes, E. E.; Henry, L.; Juban, M.; Hormes, J. Efficacy of lytic peptide-bound magnetite nanoparticles in destroying breast cancer cells. I. Nanosci. Nanotechnol. 2004, 4 (3), 245-9.

(31) Cruz, L. J.; Tacken, P. J.; Fokkink, R.; Joosten, B.; Stuart, M. C.; Albericio, F.; Torensma, R.; Figdor, C. G. I. Controlled Release 2010, 144 (2), 118-26.

(32) Bradford, M. M. A rapid and sensitive method for the quantitation of microgram quantities of protein utilizing the principle of proteindye binding. Anal. Biochem. 1976, 72, 248-54.

(33) Vitiello, A.; Ishioka, G.; Grey, H. M.; Rose, R.; Farness, P.; LaFond, R.; Yuan, L.; Chisari, F. V.; Furze, J.; Bartholomeuz, R.; et al. Development of a lipopeptide-based therapeutic vaccine to treat chronic $\mathrm{HBV}$ infection. I. Induction of a primary cytotoxic $\mathrm{T}$ lymphocyte response in humans. L. Clin. Invest. 1995, 95 (1), 341-9.

(34) Cruz, L. J.; Iglesias, E.; Aguilar, J. C.; Gonzalez, L. J.; Reyes, O.; Albericio, F.; Andreu, D. A comparative study of different presentation strategies for an HIV peptide immunogen. Bioconjugate Chem. 2004, 15 (1), 112-20.

(35) Borras-Cuesta, F.; Fedon, Y.; Petit-Camurdan, A. Enhancement of peptide immunogenicity by linear polymerization. Eur. J. Immunol. 1988, 18 (2), 199-202.

(36) Huang, S. H.; Liao, M. H.; Chen, D. H. Direct binding and characterization of lipase onto magnetic nanoparticles. Biotechnol. Prog. 2003, 19 (3), 1095-100.

(37) Verdijk, P.; Aarntzen, E. H.; Lesterhuis, W. J.; Boullart, A. C.; Kok, E.; van Rossum, M. M.; Strijk, S.; Eijckeler, F.; Bonenkamp, J. J.;
Jacobs, J. F.; Blokx, W.; Vankrieken, J. H.; Joosten, I.; Boerman, O. C.; Oyen, W. J.; Adema, G.; Punt, C. J.; Figdor, C. G.; de Vries, I. J. Limited amounts of dendritic cells migrate into the T-cell area of lymph nodes but have high immune activating potential in melanoma patients. Clin. Cancer Res. 2009, 15 (7), 2531-40.

(38) Panyam, J.; Zhou, W. Z.; Prabha, S.; Sahoo, S. K.; Labhasetwar, V. Rapid endo-lysosomal escape of poly(DL-lactide-co-glycolide) nanoparticles: implications for drug and gene delivery. FASEB J. 2002, 16 (10), 1217-26.

(39) Shen, H.; Ackerman, A. L.; Cody, V.; Giodini, A.; Hinson, E. R.; Cresswell, P.; Edelson, R. L.; Saltzman, W. M.; Hanlon, D. J. Immunology 2006, 117 (1), 78-88.

(40) Kim, D. H.; Martin, D. C. Sustained release of dexamethasone from hydrophilic matrices using PLGA nanoparticles for neural drug delivery. Biomaterials 2006, 27 (15), 3031-7.

(41) Lee, P. W.; Hsu, S. H.; Wang, J. J.; Tsai, J. S.; Lin, K. J.; Wey, S. P.; Chen, F. R.; Lai, C. H.; Yen, T. C.; Sung, H. W. Sustained release of dexamethasone from hydrophilic matrices using PLGA nanoparticles for neural drug delivery. Biomaterials 31 (6), 1316-24. 